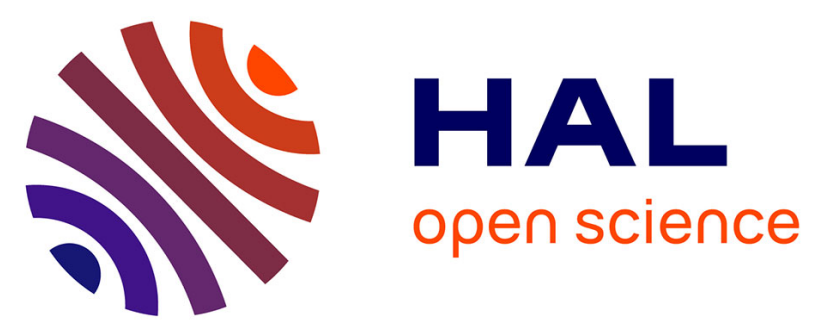

\title{
Variability of free and glycosylated volatiles from strawberries destined for the fresh market and for processing, assessed using direct enzymatic hydrolysis
}

Stéphane Gaborieau, Aurélie Cendres, David Page, Christian Ginies, Catherine M.G.C. Renard

\section{To cite this version:}

Stéphane Gaborieau, Aurélie Cendres, David Page, Christian Ginies, Catherine M.G.C. Renard. Variability of free and glycosylated volatiles from strawberries destined for the fresh market and for processing, assessed using direct enzymatic hydrolysis. LWT - Food Science and Technology, 2018, 98, pp.187-196. 10.1016/j.lwt.2018.08.026 . hal-02623748

\section{HAL Id: hal-02623748 \\ https://hal.inrae.fr/hal-02623748}

Submitted on 26 May 2020

HAL is a multi-disciplinary open access archive for the deposit and dissemination of scientific research documents, whether they are published or not. The documents may come from teaching and research institutions in France or abroad, or from public or private research centers.
L'archive ouverte pluridisciplinaire HAL, est destinée au dépôt et à la diffusion de documents scientifiques de niveau recherche, publiés ou non, émanant des établissements d'enseignement et de recherche français ou étrangers, des laboratoires publics ou privés. 


\section{Accepted Manuscript}

Variability of free and glycosylated volatiles from strawberries destined for the fresh market and for processing, assessed using direct enzymatic hydrolysis

Stephane Gaborieau, Aurelie Cendres, David Page, Christian Ginies, Catherine M.G.C. Renard

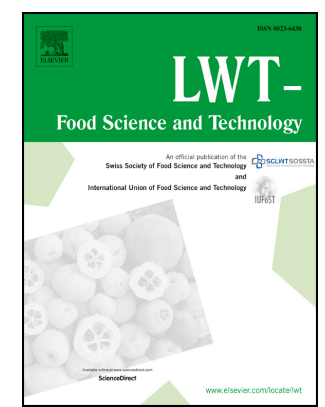

PII:

S0023-6438(18)30679-0

DOI:

10.1016/j.Iwt.2018.08.026

Reference: YFSTL 7338

To appear in: $\quad$ LWT - Food Science and Technology

Received Date: 1 February 2018

Revised Date: 26 June 2018

Accepted Date: 13 August 2018

Please cite this article as: Gaborieau, S., Cendres, A., Page, D., Ginies, C., Renard, C.M.G.C., Variability of free and glycosylated volatiles from strawberries destined for the fresh market and for processing, assessed using direct enzymatic hydrolysis, LWT - Food Science and Technology (2018), doi: 10.1016/j.Iwt.2018.08.026.

This is a PDF file of an unedited manuscript that has been accepted for publication. As a service to our customers we are providing this early version of the manuscript. The manuscript will undergo copyediting, typesetting, and review of the resulting proof before it is published in its final form. Please note that during the production process errors may be discovered which could affect the content, and all legal disclaimers that apply to the journal pertain. 
1 Title: Variability of free and glycosylated volatiles from strawberries destined for the fresh

2 market and for processing, assessed using direct enzymatic hydrolysis

3 Authors:

4 Stephane Gaborieau ${ }^{\mathrm{a}, \mathrm{b}}$, Aurelie Cendres ${ }^{\mathrm{b}}$, David Page ${ }^{\mathrm{a}}$, Christian Ginies ${ }^{\mathrm{a}}$, Catherine M.G.C.

5 Renard $^{\mathrm{a}}$

6 a UMR408 Sécurité et Qualité des Produits d'Origine Végétale, INRA, Avignon University F784000 Avignon, France

$8 \quad$ b Atelier du fruit, 7 rue des Pommerets, 21600 Longvic-FRANCE 9

9

10

11 Corresponding author :

12 Mr. Stephane Gaborieau

13

14 INRA Centre de recherche PACA, Domaine Saint-Paul, Site Agroparc

15228 route de l'Aérodrome

16 CS 40509 F-84914 Avignon Cedex 9 France

17

Tel.: +33603861398

18

E-mail: stephane.gaborieau@inra.fr 
19 Abstract: Free- and glycosylated-volatile profiles of 14 strawberry varieties, 9 for industrial

20 processing ('Darselect', 'Clery', 'Honey', 'Honeoye', 'Siabel', 'FCMO060', 'Fraise19', 2

21 'Senga Sangana') and 5 for fresh market ('Gariguette', 'Charlotte', 'CIR121', 2 'Clery' (full-

22 field and hydroponic)), were compared. All volatiles were analysed by GC-MS. Volatiles

23 from glycosides were first released by direct enzymatic hydrolysis. The extraction method

24 was optimised for furaneol, a key component of strawberry aroma. More than 60 volatile

25 compounds were identified, the most abundant being butyl acetate (average: $17 \mathrm{mg} / \mathrm{kg}$ ),

26 furaneol (average: $2 \mathrm{mg} / \mathrm{kg}$ ) and free hexanoic acid (average: $3 \mathrm{mg} / \mathrm{kg}$ ). Free-volatile profiles

27 showed a split between fresh market strawberries, distinguished by esters and carbonyl

28 molecules like isobutyl acetate or hexanal, and strawberries for processing, distinguished by

29 molecule like 3-penten-2-one and 1-butanol. The three 'Clery' profiles were different notably

30 in their hexanal, 4-vinylguaiacol and 3-penten-2-one concentrations. The glycosylated volatile

31 profiles were similar among most strawberry varieties with, as major glycosylated volatiles,

32 hexanoic acid (average: $1.7 \mathrm{mg} / \mathrm{kg}$ ), benzyl alcohol (average: $0.5 \mathrm{mg} / \mathrm{kg}$ ), gamma-decalactone

33 (average: $0.5 \mathrm{mg} / \mathrm{kg}$ ) and coumaran (average: $2.5 \mathrm{mg} / \mathrm{kg}$ ). The potential for volatile

34 enhancement by deconjugation was different. Potentially fresh market strawberries had a

35 volatile increase of $6 \%$ against $50 \%$ for strawberries for processing.

36 Keywords: glycoside, glycosidase, GC-MS, aroma, Fragaria x ananassa 


\section{Introduction}

Over 4.3 millions of tons of strawberries are produced each year, out of which $80 \%$ to 90\% are destined for the fresh market (López-Aranda et al., 2011) and the rest for processing. Strawberries are found in juices, in jams and in semi-processed food products, which can be incorporated in yogurt, ice cream or pastry. Strawberry is also the most appreciated fruit by French consumers and 92\% of them (Bhat, Geppert, Funken, \& Stamminger, 2015) like strawberries because of their specific aroma. Therefore, aromatic potential of strawberries for processing interest for future process optimisation to preserve or enhance the aromatic power of strawberries.

The molecules most impacting strawberry aroma (Nuzzi, Lo Scalzo, Testoni, \& Rizzolo, 2008) are furaneol, mesifuran, ethyl butanoate, ethyl hexanoate, $\beta$-linalool and hexanal. They are responsible for "caramel", "apple-like", "fruity" and "green" notes, respectively, in strawberries. Several molecules are not ubiquitous but are important for the aroma of strawberries in which they are found. This is the case of gamma-decalactone with "peach-like" note found in 'Elsanta' or 'Senga Sangana' varieties or trans-nerolidol with “floral” note found in 'Elvira' or 'Pandera' varieties (Larsen, Poll, \& Olsen, 1992). Despite its complexity, scientists agree that furaneol is the key molecule (Wein et al., 2002; Ulrich et al., 1997). This furanone is obtained by several successive enzymatic transformations of Dfructose-1,6-diphosphate, the last one of which is a reduction by a quinone oxidoreductase (Raab, 2006).

Various parameters can influence the aroma of strawberries (Perez, Rios, Sanz, \& Olias, 1992; Miszczak, Forney, \& Prange, 1995). The first one is genetic. Indeed Aharoni (2004) compared the aroma profile of wild strawberries (Fragaria vesca) and cultivated strawberries (Fragaria $x$ ananassa). Nerolidol dominates among terpenes in cultivated strawberries, while, in wild strawberries, monoterpenes like $\beta$-myrcene and $\alpha$-pinene, 
responsible of the characteristic musky aroma of this species, are more prevalent (Bianchi, Lovazzano, Lanubile, \& Marocco, 2014). Maturity also impacts the strawberry aroma: Forney, Kalt, \& Jordan (2000) showed an increase of methyl butanoate and methyl hexanoate with maturity and Darbellay, Luisier, Villettaz, Amadò, \& Azodanlou (2004) a decrease of (Z)-3-hexenyl acetate and an increase of ethyl hexanoate during ripening in 'Carezza', 'Darselect' and 'Marmolada' varieties. The atmosphere during packaging also impacts volatile production: Nielsen \& Leufven (2008) showed an increase of ethyl acetate (fermented molecules) with $\mathrm{CO}_{2}$-enriched atmosphere in the 'Korona' variety.

However not all volatiles exist as such in the intact raw fruit. Some are formed during eating or processing by endogenous enzymes acting on precursors. A well-known reaction cascade is that of lipoxygenase leading to "green" notes from fatty acids (Pérez, Sanz, Olías, \& Olías, 1999). Another major route is that of glycosides, where the flavour-bearing molecules (aglycones which become volatiles if liberated) are bound to sugars for storage. The sugar moiety can be a mono- or disaccharide and more rarely a trisaccharide, the first aglycone-bound sugar always being $\beta$-D-glucose (Sarry \& Gunata, 2004). These precursors are present in all fruits, including strawberries. They were studied by Stahl-Biskup, Intert, Holthuijzen, Stengele, \& Schulz (1993) in apples, apricots, blackberries, mangoes, plums and tomatoes or Gunata, Bayonove, Baumes, \& Cordonnier (1985) in grapes. In strawberries, furaneol, mesifuran, benzyl alcohol, 2-phenylethyl alcohol, hydroxylinalool, 2methylbutanoic acid or hexanoic acid can be found as glycosides (Groyne, Lognay, \& Marlier, 1999). For example furaneol is predominantly conjugated to malonyl-D-glucose (Raab, 2006).

These glycosides are traditionally identified and quantified after isolation by solid phase extraction (SPE) (Young \& Paterson, 1995). SPE consists in injecting the fruit extract on an XAD-2 or a C18-column, which binds the aglycone moieties of the glycosides. The 
sugars and free volatiles are first eluted by water and dichloromethane, respectively; the glycosides are thereafter eluted with another solvent (generally methanol) (Ubeda et al., 2012; Roscher, Herderich, Steffen, Schreier, \& Schwab, 1996). This method allows to eliminate matrix interactions. However, it is not adapted to compare free volatiles to bound volatiles because of the discrimination that is generated by affinity extraction, and because the natural evolution of volatiles in fruit matrices is not considered. Indeed, Hampel, Robinson, Johnson, \& Ebeler (2014) showed that this pre-treatment leads to a loss and a discrimination of many compounds, and can not be used to compare free volatile to glycoconjugated volatiles. They advised direct hydrolysis to compare quantitatively free and bound volatiles.

The aim of this study is to establish direct hydrolysis by AR2000 glycosidase as a method to compare aroma profiles and aromatic potentials of processing and fresh market strawberries. Fourteen strawberry batches, 9 for processing (obtained from industrial sources) and 5 for fresh market (obtained from CIREF (Centre Interrégional de Recherche et d'Expérimentation de la Fraise, Douville (France)) were characterised. Direct enzymatic hydrolysis was combined with GC-MS analysis and descriptive statistics to evaluate aromatic potential of these strawberries.

\section{Material \& method}

\subsection{Plant material}

Strawberries for processing were commercial samples harvested in 2015, individually quick frozen (IQF), and stored at $-20^{\circ} \mathrm{C}$. Among them, 'FCMO' and 'Fraise19' are a mix of several strawberry varieties used by the French food industry. Fresh market strawberries were from CIREF, harvested in 2016 , and were frozen at $-20^{\circ} \mathrm{C}$ (Table 1).

\subsection{Reagents and solvents}


Pentane (Normapur purity $\geq 99.9 \%$ ) and Ethyl acetate (purity $\geq 99.9 \%$ ) were purchased

113 from VWR International (Darmstadt, Germany). Enzymatic kits to measure D-

114 glucose/fructose (ref: E 0139106), D-glucose (ref: E 0716251), L-malic acid (ref: E 0139 068)

115 and citric acid (ref: E 0139076) were from R-Biopharm (Darmstadt, Germany).

116 Hydromatrix ${ }^{\mathrm{TM}}$ (diatomaceous earth) was from Agilent Technologies (Les Ulys, France). The

117 internal standard was 4-nonanol (purity > $97 \%$ ) from Merck Schuchardt (Hohenbrunn,

118 Germany). The AR2000 enzyme to measure the aromatic potential came from Oenobrands

119 (Montferrier-sur-Lez, France) as freeze-dried powder (6.17 nkat/mg of powder). For retention

120 index (RI) calculations in GC-MS, a solution of C7-C30 saturated alkane $1000 \mu \mathrm{g} / \mathrm{mL}$ (ref:

121 49451-U) from Supelco (Bellefonte, Pennsylvania, USA) was used.

122

\section{2.3. Fruit characterisation}

124

\subsection{Brix and $p H$}

125

Strawberries (about $100 \mathrm{~g}$ ) were ground and used for measurement of Brix degree

using a digital refractometer PR-101 from Agato (Tokyo, Japan) and of $\mathrm{pH}$ using pHmeter

127 FE20 FireEasy from Mettler Toledo (Viroflay, France).

128

129

130

131

132

133

134

135

136

\subsubsection{Sugars and Acids}

Sugars (glucose, fructose, sucrose) and main organic acids (citric acid and malic acid)

were quantified by colorimetric enzymatic measurements with kits for food analysis from R-

Biopharm (Darmstadt, Germany) and expressed in g.kg ${ }^{-1} \mathrm{FW}$. The measurements were performed on a 96 well-microplate with a SAFAS (FLX-Xenius, SAFAS, Monaco) equipped with an automatic injection device (Garcia \& Renard, 2014).

\subsection{Characterization of Volatiles Compounds}

\subsubsection{Sample preparation:}


A dozen of frozen strawberries (around $150 \mathrm{~g}$ ) were mashed for $1 \mathrm{~min}$ in a blender

138 (Waring-Nova, Grosseron, St. Herblain, France) (Figure 1). An aliquot (40 g) was sampled

139 for enzymatic hydrolysis with $40 \mathrm{mg}$ of AR2000. Sodium chloride was added to the rest of

140 the mashed strawberries (75 g/100 g of strawberry) to inhibit endogenous enzymes. After

141 another mixing, this was divided: one aliquot of $40 \mathrm{~g}$ used for incubation (hydrolysis negative

142 control) and an aliquot for direct extraction (determination of free volatiles). After incubation

$143\left(24 \mathrm{~h}, 40^{\circ} \mathrm{C}\right.$ with stirring at $120 \mathrm{rpm}$ ), salt was added to the hydrolysed aliquots to have the

144 same salting-out effect during extraction of volatile compounds by accelerated solvent 145 extraction.

\subsubsection{Accelerated solvent extraction (ASE)}

148 internal standard, were mixed with $7.5 \mathrm{~g}$ of mashed fruit to obtain a homogeneous powder

149 while inactivating enzymes. The powder was rapidly transferred to a $33 \mathrm{~mL}$ pressurized

150 extraction cell for immediate extraction. The extractor was an ASE 200 system (Dionex,

151 Sunnyvale, CA). Extraction conditions were as follows: pentane and ethyl acetate (1:2,

$152 \mathrm{~mL}: \mathrm{mL}$ ) as solvent, $10^{7} \mathrm{~Pa}, 40^{\circ} \mathrm{C}, 5 \mathrm{~min}$ preheating then $5 \mathrm{~min}$ static incubation. The extract

153 was concentrated to $1 \mathrm{~mL}$ by distillation under vacuum $\left(300 \mathrm{~Pa}, 25^{\circ} \mathrm{C}\right.$, using a Multivapor

154 R12, Büchi, Rungis, France) then by nitrogen flux prior to gas chromatography.

155

156

157

158

159

160

\subsubsection{GC-MS}

Samples $(1 \mu \mathrm{L})$ were injected into a GC-MS system (Trace1300-ISQ LT; Thermo scientific, USA) equipped with a TG-WAXMS capillary column $[30 \mathrm{~m}, 0.25 \mathrm{~mm}$ i.d., $0.5 \mu \mathrm{m}$ film thickness] (Thermo scientific).

Injection was in splitless mode at $250^{\circ} \mathrm{C}$. The carrier gas was helium with a constant flow of $1.2 \mathrm{~mL} \cdot \mathrm{min}^{-1}$. Oven temperature program was $35^{\circ} \mathrm{C}$ for $2 \mathrm{~min}$ ramped at $5^{\circ} \mathrm{C} \cdot \mathrm{min}^{-1}$ to $230^{\circ} \mathrm{C}$ 
161 then held for $5 \mathrm{~min}$. Mass spectra were obtained by electron ionization at $70 \mathrm{eV}$, with

162 scanning from $\mathrm{m} / \mathrm{z} 35$ to 250 at 2 scans.s ${ }^{-1}$.

163 Volatile levels were expressed in micrograms per kilograms of juice (ppb) in 4-

164 nonanol equivalent. Aromatic potential was calculated by difference between hydrolysed

165 samples and incubated control samples. This aromatic potential was compared to the initial

166 free volatile profile to observe molecules increase or decrease. Aromatic potential

167 corresponds to glycoconjugates released by AR2000 and the evolution of these molecules and

168 original free volatiles under action of endogenous enzymes.

169 Data were collected with GC-MS Solution software Chromeleon 7.2 and, when it was

170 possible, the major compounds were identified by their retention index and their mass spectra

171 using the mass spectral database NIST 14 (US National Institute of Standards and Technology

172 (NIST), Gaithersburg, MD, USA)].

173

174

\subsection{Statistics}

175

For each batch, three samples of twelve strawberries each were analyzed. Principal

176 Component Analysis (PCA) was performed with XLSTAT software (Addinsoft, France) to

177 compare the 14 strawberry varieties with quantified volatiles as variables. Correlation factor 178 was calculated by Pearson's method.

179

\section{3. Results}

$181 \quad 3.1$ General characteristics of the strawberries

182 Global characteristics of the strawberry are summarized in Table 1. The average pH

183 was 3.5 and the average Brix degree was between 8 9. This is coherent with previous studies

184 (Schwieterman et al., 2014). The main acid was citric acid but with a high proportion ( 30\%)

185 of malic acid. Acid concentrations were similar among all strawberries (fresh market or for 
processing). Glucose, fructose and sucrose are present in similar proportions (around 30\% for

187 glucose, $45 \%$ for fructose and $25 \%$ for sucrose) among the strawberries for processing while

188 table strawberries had no sucrose but had higher fructose and glucose concentrations. In

189 strawberries, sucrose does not vary during ripening (Sturm, Koron, \& Stampar, 2003) so this

190 difference can not be explained by a simple difference of maturity. Interestingly, the three

191 Clery samples had similar pH but different Brix degree (7.8 for Clery; 6.9 for Clery PC; 8.6

192 for Clery HS) with an absence of sucrose for Clery PC and Clery HS from CIREF.

193

194

195

196

197

198

199

200

201

202

203

204

205

206

207

208

209

\subsection{Optimisation of volatile extraction}

The extraction solvent was optimized for furaneol, being a key molecule for strawberry aroma. In a pre-test, a synthetic solution of furaneol $(0.5 \mathrm{~g} / \mathrm{L})$ was extracted by $\mathrm{n}$ pentane/dichloromethane (2:1 $\mathrm{mL}: \mathrm{mL})$, dichloromethane or $\mathrm{n}$-pentane/ethyl acetate $(1: 2$ $\mathrm{mL}: \mathrm{mL})$. One millilitre of this standard solution was extracted with $1 \mathrm{~mL}$ of solvent three times and extracts were injected after concentration. Extraction yields were of $27 \%$ with npentane/dichloromethane, $65 \%$ with dichloromethane and $90 \%$ with n-pentane/ethyl acetate, which was therefore retained as solvent for all subsequent extractions. This comparison was completed by ASE on strawberry purees and out of 34 quantified compounds (Figure 2), 30 compounds had a better extraction yield with n-pentane/ethyl acetate $(1: 2 \mathrm{~mL}: \mathrm{mL})$ compared to 4 compounds (isobutyl acetate, 3-penten-2-ol, acetoin and 4-methylpentan-2-ol) for dichloromethane. N-pentane/dichloromethane $(2: 1 \mathrm{~mL}: \mathrm{mL})$ seemed to be the worst solvent for strawberry volatile extraction. N-pentane/ethyl acetate was thus selected to extract volatiles from strawberries for this study.

\subsection{Identification of volatiles}


More than 60 volatile compounds were detected and identified (Table 2). Most

211 representative compounds of a strawberry aroma were found: furaneol, mesifuran, ethyl

212 butanoate, gamma-decalactone, $\beta$-linalool, trans-nerolidol, butyl acetate, ethyl hexanoate,

213 butanoic acid, isobutanoic acid and hexanoic acid (Larsen et al., 1992 ; Ménager, Jost, \&

214 Aubert, 2004 ; Schwieterman et al., 2014 ; Ubeda, Callejón, Troncoso, Morales, \& Garcia-

215 Parrilla, 2014 ; Lambert, Demazeau, Largeteau, \& Bouvier, 1999 ; Darbellay et al., 2004).

216 Some molecules, like 2-phenylethyl alcohol (rose aroma) or 1-terpineol (citrus aroma), were

217 only detected after glycoconjugate release. Cinnamic acid, another characteristic molecule of

218 strawberry, was also found but it had a variability too large to be considered in interpreting

219 the results. In the same triplicate, it can be absent or present in a quantity higher than 10

$220 \mathrm{mg} / \mathrm{kg}$.

\subsection{Free volatiles profile}

Free volatiles profiles (Suppl. data) were analyzed by PCA (Figure 3) and their repartition by chemical class is presented in Table 3. The sample map (Figure 3.a.) showed two groups of samples. The first principal component clearly separated strawberries for processing from fresh market strawberries while the second principal component differentiated 'Darselect' from all others. Each initial batch was distinct from the others except 'Fraise19' and 'FCM0', which were co-located. These two "varieties" come from a mix used by food industry, which may explain the similitudes between them. The correlation 230 circle (Figure 3.b.) indicated that strawberries for processing are differentiated by volatiles 231 like 2,3-butanediol, pantolactone, acetoin, 3-phenylpropyl alcohol or butanoic acid. Molecules 232 like benzyl alcohol, caprolactones, octanoic acid and 5-(hydroxymethyl)-2-furfural with, 233 respectively, floral, fruity, acidic and caramel notes, seemed responsible for the 'Darselect' 234 differentiation. Fresh market strawberries were differentiated by carbonyls and esters like 
235 hexanal, 3-methylbutyl acetate, isobutyl acetate, 2-hexanone. Again the three 'Clery' batches

236 were distinct, indicating that their volatile profile would not depend only on genetics but also

237 on cultivation method and pedoclimatic conditions.

238 The variety 'Gariguette' was distinguished by methyl hexanoate, 2-methylbutanoic 239 acid and isobutyric acid.

240 Fresh market strawberries (Table 3) had on average three times as much volatile 241 compounds as strawberries for processing, and esters as the most abundant molecules, 242 whereas strawberries for processing were rich in acids, except for 'Darselect,' which was rich 243 in esters.

\subsection{Glycoconjugated volatile profile}

Glycoconjugated volatile profiles (Suppl. data) were analyzed by PCA (Figure 4) and their repartition by chemical class is presented in Table 4.

Alcohols and acids were preponderantly present as glycoconjugates rather than free volatiles. They represent on average $50 \%$ of the glycosides. 'Senga Sangana' (Bulgaria) had the highest glycoside concentration and also the highest concentration of glycoconjugated ketones. The highest concentration of glycoconjugated furans, of which furaneol glycoside was the most abundant, was found in 'Siabel' ( $45 \%$ of total glycoconjugates). 'Darselect' was also different from other varieties in glycoconjugates, as it had a very low concentration of coumaran (in "other compounds") and a high level of lactones (25\% of total glycoconjugates). 'Darselect', 'Senga Sangana' (Bulgaria) and 'Gariguette' (but this last with very high variability), were clustered in the center of the PCA sample map, indicating that their 
others. 'Senga Sangana' (Bulgaria) was differentiated by 2- and 3-hexenoic acid, 1,2-

261 cyclopentanedione and phenol. Finally, 2-hexanone, propanoic acid, acetoin, 2-

262 hydroxyfuraneol and isobutanoic acid were glycoconjugates specific to 'Gariguette'.

Although strawberries for processing and fresh market strawberries had generally

264

265

266

267

\section{Discussion}

\subsection{Methodology}

Glycosides are generally quantified using a SPE pre-treatment but this separation technique, by affinity, may not be optimal to assess quantitatively free volatiles and glycosides. By this method, Roscher, Koch, Herderich, Schreier, \& Schwab (1997) estimated the glycosylated furaneol to be between $66 \%$ and $750 \%$ of the free furaneol in strawberries, whereas in this study it represented on average $14 \%$ of free furaneol (except in 'Gariguette' where bound furaneol was more than twice the amount of free furaneol). Hampel et al. (2014) confirmed obtaining differing results depending on the method with many molecules, like for 1-nonanol in 'Cabernet Sauvignon', which is multiplied by approximately 7 after direct hydrolysis and by more than 22 using the SPE method. The differences are also qualitative. They identified 95 new compounds using direct hydrolysis by glycosidases, to be compared to only 67 using the SPE method in the Chardonnay grapes. Furthermore, they observed that 24 volatiles are significantly increased and 5 decreased using direct hydrolysis as opposed to 
SPE, which showed an increase for 17 compounds and a decrease for 13 compounds. Hampel et al. (2014) assumed that glycosides of terpenes are more retained on SPE columns, which is confirmed by Baek \& Cadwallader (1999). Hampel et al. (2014) have a similar result on melon. Voirin's thesis (1990) confirms these observations on grape. He obtained an SPE yield of $15 \%$ for glycosides with phenyl-type aglycone and $70 \%$ to $100 \%$ for glycosides of terpene aglycones.

\subsection{Volatile molecules of strawberries}

Although furaneol is the key molecule for strawberry aroma, it was not qualitatively discriminant to compare volatile profile, as expected because it is ubiquitous in strawberries. This molecule is already found when strawberry volatiles are analyzed by liquid extraction (Larsen et al., 1992; Lambert et al., 1999) and sometimes found with solid phase microextraction (SPME)/headspace (Darbellay et al., 2004) which confirms this conclusion. The comparisons have to rely on other molecules. reference articles but only 3-methylbutyl acetate and 2-methylbutanoic acid were found here (as identified by their retention index and MS spectra). These molecules come from two different amino acids, L-leucine (for 3-methylbutyl/butanoate) and L-isoleucine (for 2butyl compounds. The C6 carbonyls 3-hexenal and 2-hexenal with their green odor types, other important molecules of strawberry aroma, were absent. This was expected in the aliquots which were salted during mashing as this treatment aims to inhibit the endogenous enzymes of the lipoxygenase (LOX) pathway. This absence could also be explained by their 
1998) or hexenoic acid by oxidation in AR2000-treated samples. Indeed, although 2- and 3-

311 hexenal were not found, 2- and 3-hexenoic acid (quantifiable) and 3-hexenol (not

312 quantifiable) were present. The identified volatiles had mainly fruity or floral odor type.

313 These differences could arise from extraction with ethyl acetate/n-pentane (2:1), which is

314 more polar than dichloromethane (the usual solvent) and the long incubation time (overnight)

315 allowing chemical degradation. Between control samples with and without incubation,

316 decreases of molecules like 2-methylbutanoic acid and hexanoic acid and increases of

317 molecules like 2-hexenoic acid and 2-hydroxy-4-pyranone were observed and some

318 molecules became undetectable like ethyl cinnamate and ethyl hexanoate.

\subsection{Comparison of industrial and fresh-market strawberries}

\section{Free volatiles}

The differentiation between industrial and fresh market strawberry aroma profiles may

explain their different uses, resulting from distinct selection goals. Strawberries for processing

need to keep their texture and color after treatment especially in dairy products. Fresh market

strawberries, which are produced to be eaten as-is, need to have a good instant aromatic

quality to attract consumers. This is reflected in the present results by generally higher

contents of free volatiles in the fresh-market strawberries. Zorrilla-Fontanesi et al., (2012)

studied the natural genetic variability of aroma in strawberry. They compared genomes of

probably could be interesting to complete this comparison between strawberries for process

331 and for fresh market. An interesting point was that the 3 studied 'Clery' have different

332 volatiles profiles. These differences can not be explained only by genetics especially

333 considering that the two samples from CIREF come from the same cultivar and were grown at

334 the same location. The only difference was that one sample was in full-field and the other in 
335 hydroponics. The cultivation method also appeared to have a non-negligible effect on aroma 336 profile.

\section{Glycoconjugated volatiles}

However limited differences were observed between fresh-market and industrial

strawberries in the case of glycoconjugated volatiles. Indeed previous studies (Ubeda et al.,

341 2012; Groyne et al., 1999) found as main glycoconjugated volatiles in strawberries furaneol,

342 benzyl alcohol, 2-phenylethyl alcohol, 4-vinylphenol, 4-vinylguaiacol and hexanoic acid.

343 Results are consistent with literature for 'Gariguette' where Lambert et al. (1999) found also

344 methyl hexanoate, 2-methylbutanoic acid as well as hexanoic acid as main glycoconjugated

345 volatiles. Except for 4-vinylphenol, all were also found in this study. The importance of

346 glycoconjugates of benzyl alcohol and 2-phenylethyl alcohol in strawberries was confirmed

347 by the low discriminant effect of these molecules in the glycoconjugates profiles. Among

348 released aglycones some molecules are interesting for flavor thanks their low thresholds, like

349 2-phenylethyl alcohol (rose note) with a threshold of $4 \mu \mathrm{g} / \mathrm{kg}$ (4 parts per billion (ppb)

350 (Fenaroli's Handbbok, 2010), furaneol (caramelic note) with a threshold of $0.03 \mu \mathrm{g} / \mathrm{kg}$ or $\gamma$ -

351 decalactone (peach note) with a threshold of $11 \mu \mathrm{g} / \mathrm{kg}$. These increases show that

352 deglycosylation could be a way to enrich natural aroma extracts.

\section{Conclusion}

Direct enzymatic hydrolysis allowed to reexamine the free to glycoconjugated volatile

ratios in strawberries. Free volatiles were more abundant than glycoconjugated volatiles, especially in fresh market strawberries, and that the glycosylated/free volatiles ratio was 
release of glycoconjugated volatiles would enhance aroma in a similar manner for all

361 varieties. It can therefore be an interesting way to enhance the aromatic power of strawberry

362 preparations in industry. Besides fresh market strawberries had a lower aromatic reserve,

363 which indicates that strawberries for processing would be better candidates for future

364 experiments on glycoside hydrolysis during process.

365

366

367

368

\section{Acknowledgments}

369

This work was supported by funds obtained from BPI (Banque pour l'Investissement)

370 région Bourgogne-Franche Comté, région Provence Alpes Côte d'Azur, France, Europe,

371 FEDER (fonds européen de développement régional), Grand-Dijon, and Grand-Avignon, in

372 the form of Fond Unique Interministériel. The project name is Natarome+. The project is co-

373 labeled by Terralia and Vitagora.

374 
Aharoni, A. (2004). Gain and Loss of Fruit Flavor Compounds Produced by Wild and Cultivated Strawberry Species. The Plant Cell Online, 16(11), 3110-3131. https://doi.org/10.1105/tpc.104.023895

Baek, H. H., \& Cadwallader, K. R. (1999). Contribution of Free and Glycosidically Bound Volatile Compounds to the Aroma of Muscadine Grape Juice. Journal of Food Science, 64(3), 441-444. https://doi.org/10.1111/j.1365-2621.1999.tb15059.x

Bhat, R., Geppert, J., Funken, E., \& Stamminger, R. (2015). Consumers Perceptions and Preference for Strawberries-A Case Study from Germany. International Journal of Fruit Science, 15(4), 405-424. https://doi.org/10.1080/15538362.2015.1021408

Bianchi, G., Lovazzano, A., Lanubile, A., \& Marocco, A. (2014). Aroma Quality of Fruits of Wild and Cultivated Strawberry (FRAGARIA SPP.) in Relation to the FlavourRelated Gene Expression. Journal of Horticultural Research, 22(1). https://doi.org/10.2478/johr-2014-0009

Burdock, G. A., \& Fenaroli, G. (2010). Fenaroli's handbook of flavor ingredients (6th ed). Boca Raton: CRC Press/Taylor \& Francis Group.

Darbellay, C., Luisier, J.-L., Villettaz, J.-C., Amadö, R., \& Azodanlou, R. (2004). Changes in flavour and texture during the ripening of strawberries. European Food Research and Technology, 218(2), 167-172. https://doi.org/10.1007/s00217-003-0822-0

Forney, C. F., Kalt, W., \& Jordan, M. A. (2000). The composition of strawberry aroma is influenced by cultivar, maturity, and storage. HortScience, 35(6), 1022-1026.

Garcia, C., \& Renard, C. (2014). Validation des dosages enzymatiques des sucres (glucose, fructose, saccharose) et acides (acide citrique et malique) par un spectrophotomètre avec lecteur de microplaques. Cahier des Techniques de l'INRA, 81(1), 18. 
Groyne, J., Lognay, G., \& Marlier, M. (1999). Accumulation of glycosidically bound

400

401

402

403

404

405

406

407

408

409

410

411

412

413

414

415

416

417

418

419

420

421

422 compounds in Fragaria* ananassa cv. Elsanta fruits at various developmental stages. Biotechnologie, Agronomie, Société et Environnement= Biotechnology, Agronomy, Society and Environment [= BASE], 3(1), 5-9.

Gunata, Y. Z., Bayonove, C. L., Baumes, R. L., \& Cordonnier, R. E. (1985). The aroma of grapes I. Extraction and determination of free and glycosidically bound fractions of some grape aroma components. Journal of Chromatography A, 331, 83-90. https://doi.org/10.1016/0021-9673(85)80009-1

Hampel, D., Robinson, A. L., Johnson, A. J., \& Ebeler, S. E. (2014). Direct hydrolysis and analysis of glycosidically bound aroma compounds in grapes and wines: comparison of hydrolysis conditions and sample preparation methods: Glycoside analysis. Australian Journal of Grape and Wine Research, 20(3), 361-377. https://doi.org/10.1111/ajgw.12087

Lambert, Y., Demazeau, G., Largeteau, A., \& Bouvier, J.-M. (1999). Changes in aromatic volatile composition of strawberry after high pressure treatment. Food Chemistry, 67(1), 7-16. https://doi.org/10.1016/S0308-8146(99)00084-9

Larsen, M., Poll, L., \& Olsen, C. E. (1992). Evaluation of the aroma composition of some strawberry (Fragaria ananassa Duch) cultivars by use of odour threshold values. Zeitschrift für Lebensmittel-Untersuchung und -Forschung, 195(6), 536-539. https://doi.org/10.1007/BF01204558

López-Aranda, J. M., Soria, C., Santos, B. M., Miranda, L., Domínguez, P., \& MedinaMínguez, J. J. (2011). Strawberry Production in Mild Climates of the World: A Review of Current Cultivar Use. International Journal of Fruit Science, 11(3), 232244. https://doi.org/10.1080/15538362.2011.608294 
Ménager, I., Jost, M., \& Aubert, C. (2004). Changes in Physicochemical Characteristics and Volatile Constituents of Strawberry (Cv. Cigaline) during Maturation. Journal of Agricultural and Food Chemistry, 52(5), 1248-1254. https://doi.org/10.1021/jf0350919

Miszczak, A., Forney, C. F., \& Prange, R. K. (1995). Devlopment of Aroma volatiles and color during postharvest ripening of "Kent" strawberries. Journal of the American Society for Horticultural Science, 120(4), 650-655.

Nielsen, T., \& Leufven, A. (2008). The effect of modified atmosphere packaging on the quality of Honeoye and Korona strawberries. Food Chemistry, 107(3), 1053-1063. https://doi.org/10.1016/j.foodchem.2007.09.025

Nuzzi, M., Lo Scalzo, R., Testoni, A., \& Rizzolo, A. (2008). Evaluation of Fruit Aroma Quality: Comparison Between Gas Chromatography-Olfactometry (GC-O) and Odour Activity Value (OAV) Aroma Patterns of Strawberries. Food Analytical Methods, 1(4), 270-282. https://doi.org/10.1007/s12161-008-9039-y

Pérez, A. G., Olías, R., Luaces, P., \& Sanz, C. (2002). Biosynthesis of Strawberry Aroma Compounds through Amino Acid Metabolism. Journal of Agricultural and Food Chemistry, 50(14), 4037-4042. https://doi.org/10.1021/jf011465r

Perez, A. G., Rios, J. J., Sanz, C., \& Olias, J. M. (1992). Aroma components and free amino acids in strawberry variety Chandler during ripening. Journal of Agricultural and Food Chemistry, 40(11), 2232-2235. https://doi.org/10.1021/jf00023a036

Pérez, A. G., Sanz, C., Olías, R., \& Olías, J. M. (1999). Lipoxygenase and Hydroperoxide Lyase Activities in Ripening Strawberry Fruits. Journal of Agricultural and Food Chemistry, 47(1), 249-253. https://doi.org/10.1021/jf9807519 
Raab, T. (2006). FaQR, Required for the Biosynthesis of the Strawberry Flavor Compound 4Hydroxy-2,5-Dimethyl-3(2H)-Furanone, Encodes an Enone Oxidoreductase. THE PLANT CELL ONLINE, 18(4), 1023-1037. https://doi.org/10.1105/tpc.105.039784

Roscher, R., Koch, H., Herderich, M., Schreier, P., \& Schwab, W. (1997). Identification of 2,5-dimethyl-4-hydroxy-3[2H]-furanone $\beta$-D-glucuronide as the major metabolite of a strawberry flavour constituent in humans. Food and Chemical Toxicology, 35(8), 777782. https://doi.org/10.1016/S0278-6915(97)00055-0

Roscher, René, Herderich, M., Steffen, J.-P., Schreier, P., \& Schwab, W. (1996). 2,5-

454

455

Dimethyl-4-hydroxy-3[2H]-furanone 6'O-malonyl- $\beta$-D-glucopyranoside in strawberry fruits. Phytochemistry, 43(1), 155-159. https://doi.org/10.1016/0031-9422(96)00216-6

Sarry, J., \& Gunata, Z. (2004). Plant and microbial glycoside hydrolases: Volatile release from glycosidic aroma precursors. Food Chemistry, 87(4), 509-521. https://doi.org/10.1016/j.foodchem.2004.01.003

Schwieterman, M. L., Colquhoun, T. A., Jaworski, E. A., Bartoshuk, L. M., Gilbert, J. L., Tieman, D. M., ... Clark, D. G. (2014). Strawberry Flavor: Diverse Chemical Compositions, a Seasonal Influence, and Effects on Sensory Perception. PLoS ONE, 9(2), e88446. https://doi.org/10.1371/journal.pone.0088446

Speirs, J., Lee, E., Holt, K., Yong-Duk, K., Steele Scott, N., Loveys, B., \& Schuch, W. (1998). Genetic Manipulation of Alcohol Dehydrogenase Levels in Ripening Tomato Fruit Affects the Balance of Some Flavor Aldehydes and Alcohols. Plant Physiology, 117(3), 1047-1058. https://doi.org/10.1104/pp.117.3.1047

Stahl-Biskup, E., Intert, F., Holthuijzen, J., Stengele, M., \& Schulz, G. (1993). Glycosidically bound volatiles_a review 1986-1991. Flavour and Fragrance Journal, 8(2), 61-80. https://doi.org/10.1002/ffj.2730080202 
Sturm, K., Koron, D., \& Stampar, F. (2003). The composition of fruit of different strawberry varieties depending on maturity stage. Food Chemistry, 83(3), 417-422. https://doi.org/10.1016/S0308-8146(03)00124-9

Ubeda, C., Callejón, R. M., Troncoso, A. M., Morales, M. L., \& Garcia-Parrilla, M. C. (2014). Influence of the production process of strawberry industrial purees on free and glycosidically bound aroma compounds. Innovative Food Science \& Emerging Technologies, 26, 381-388. https://doi.org/10.1016/j.ifset.2014.02.015

Ubeda, Cristina, San-Juan, F., Concejero, B., Callejón, R. M., Troncoso, A. M., Morales, M. L., ... Hernández-Orte, P. (2012). Glycosidically Bound Aroma Compounds and Impact Odorants of Four Strawberry Varieties. Journal of Agricultural and Food Chemistry, 60(24), 6095-6102. https://doi.org/10.1021/jf301141f

Ulrich, D., Hoberg, E., Rapp, A., \& Kecke, S. (1997). Analysis of strawberry flavour discrimination of aroma types by quantification of volatile compounds. Zeitschrift für Lebensmitteluntersuchung und -Forschung A, 205(3), 218-223. https://doi.org/10.1007/s002170050154

Voirin, S. (1990, April 23). Connaissance de l'arôme du raisin: analyses et synthèses de précurseurs hétérosidiques (Thèse en doctorat de Biochimie. Biologie moléculaire et cellulaire). Montpellier 2, Montpellier. Retrieved from http://www.theses.fr/1990MON20074

Wein, M., Lavid, N., Lunkenbein, S., Lewinsohn, E., Schwab, W., \& Kaldenhoff, R. (2002). Isolation, cloning and expression of a multifunctional O-methyltransferase capable of forming 2,5-dimethyl-4-methoxy-3(2H)-furanone, one of the key aroma compounds in strawberry fruits. The Plant Journal, 31(6), 755-765. https://doi.org/10.1046/j.1365313X.2002.01396.x 
494 Young, H., \& Paterson, V. J. (1995). Characterisation of bound flavour components in

495 kiwifruit. Journal of the Science of Food and Agriculture, 68(2), 257-260.

496 Zorrilla-Fontanesi, Y., Rambla, J.-L., Cabeza, A., Medina, J. J., Sanchez-Sevilla, J. F.,

497

Valpuesta, V., ... Amaya, I. (2012). Genetic Analysis of Strawberry Fruit Aroma and

498

Identification of O-Methyltransferase FaOMT as the Locus Controlling Natural

499

Variation in Mesifurane Content. Plant Physiology, 159(2), 851-870.

500

https://doi.org/10.1104/pp.111.188318

501 
Table 1: Physico-chemical characteristics and origin of strawberries material

\begin{tabular}{|c|c|c|c|c|c|c|c|c|c|}
\hline & Origin & Harvest year & Glucose $^{a}$ & Fructose $^{a}$ & Sucrose $e^{a}$ & Citric acid ${ }^{a}$ & Malic acid ${ }^{a}$ & Brix & $p H$ \\
\hline FCMO060 & Spain & 2015 & $1.59 \pm 0.11$ & $2.26 \pm 0.08$ & $1.94 \pm 0.37$ & $0.50 \pm 0.05$ & $0.28 \pm 0.01$ & $6.1 \pm 0.2$ & $3.6 \pm 0.2$ \\
\hline Siabel & Bulgaria & 2015 & $1.75 \pm 0.25$ & $2.49 \pm 0.08$ & $1.41 \pm 0.35$ & $0.70 \pm 0.08$ & $0.31 \pm 0.03$ & ND & $3.5 \pm 0.2$ \\
\hline Clery & $?$ & 2015 & $2.12 \pm 0.31$ & $3.19 \pm 0.46$ & $1.88 \pm 0.32$ & $0.40 \pm 0.01$ & $0.18 \pm 0.01$ & $7.8 \pm 0.2$ & $3.7 \pm 0.2$ \\
\hline Honeoye & Bulgaria & 2015 & $2.30 \pm 0.28$ & $2.92 \pm 0.33$ & $1.91 \pm 0.40$ & $0.62 \pm 0.09$ & $0.27 \pm 0.03$ & $8.6 \pm 0.3$ & $3.8 \pm 0.2$ \\
\hline Honey & China & 2015 & $1.37 \pm 0.28$ & $2.20 \pm 0.26$ & $0.96 \pm 0.02$ & $0.46 \pm 0.02$ & $0.18 \pm 0.03$ & $6.2 \pm 0.2$ & $3.7 \pm 0.2$ \\
\hline Senga sangana & Bulgaria & 2015 & $2.49 \pm 0.31$ & $2.83 \pm 0.34$ & $2.32 \pm 0.27$ & $0.70 \pm 0.20$ & $0.37 \pm 0.01$ & $9.7 \pm 0.3$ & $3.5 \pm 0.2$ \\
\hline Darselect & Germany & 2015 & $2.36 \pm 0.62$ & $2.84 \pm 0.17$ & $1.43 \pm 0.30$ & $0.66 \pm 0.21$ & $0.18 \pm 0.01$ & $8.4 \pm 0.3$ & $3.5 \pm 0.2$ \\
\hline Senga sangana & Poland & 2015 & $1.59 \pm 0.48$ & $2.40 \pm 0.37$ & $1.17 \pm 0.13$ & $0.50 \pm 0.02$ & $0.25 \pm 0.05$ & $7.7 \pm 0.3$ & $3.4 \pm 0.2$ \\
\hline Fraise 19 & Morocco & 2016 & $1.42 \pm 0.17$ & $1.97 \pm 0.35$ & $0.73 \pm 0.38$ & $0.36 \pm 0.22$ & $0.19 \pm 0.01$ & $6.4 \pm 0.2$ & $3.6 \pm 0.2$ \\
\hline CIR121 & France (CIREF) & 2016 & $3.00 \pm 0.04$ & $2.94 \pm 0.12$ & 0.00 & $0.81 \pm 0.02$ & $0.29 \pm 0.00$ & $9.0 \pm 0.3$ & $3.7 \pm 0.2$ \\
\hline Clery PC & France (CIREF) & 2016 & $2.39 \pm 0.03$ & $2.39 \pm 0.11$ & 0.00 & $0.59 \pm 0.03$ & $0.19 \pm 0.00$ & $6.9 \pm 0.2$ & $3.5 \pm 0.2$ \\
\hline Clery HS & France (CIREF) & 2016 & $2.91 \pm 0.07$ & $2.83 \pm 0.35$ & 0.00 & $0.94 \pm 0.03$ & $0.25 \pm 0.01$ & $8.6 \pm 0.3$ & $3.5 \pm 0.2$ \\
\hline Charlotte & France (CIREF) & 2016 & $3.60 \pm 0.04$ & $3.67 \pm 0.19$ & 0.00 & $0.73 \pm 0.02$ & $0.21 \pm 0.00$ & $11.1 \pm 0.3$ & $3.9 \pm 0.2$ \\
\hline Gariguette & France (CIREF) & 2016 & $2.80 \pm 0.15$ & $2.76 \pm 0.26$ & 0.00 & $0.96 \pm 0.04$ & $0.35 \pm 0.01$ & $9.0 \pm 0.3$ & $3.4 \pm 0.2$ \\
\hline
\end{tabular}


Table 2 : Identified ${ }^{\mathrm{a}}$ volatile compound in GC-MS analyses of strawberries samples

\begin{tabular}{rcccc}
\hline & $\begin{array}{c}\text { Calculated } \\
\mathbf{R I}^{\mathbf{b}}\end{array}$ & $\begin{array}{c}\text { Perception } \\
\text { threshold in water } \\
(\boldsymbol{\mu g} / \mathbf{L})\end{array}$ & Odortype & Ref $^{\mathbf{c}, \mathbf{d}}$ \\
\hline Acids & & & & \\
(E)-2-Hexenoic acid & 1980 & NA & fruity & 7 \\
2-Mehtylbutanoic acid & 1662 & 180 & acidic & $1 ; 2 ; 3 ; 6 ; 7$ \\
3-Hexenoic acid & 1954 & NA & cheesy & 7 \\
3-Methylhexanoic acid & 1916 & NA & - & cheesy \\
Butanoic acid & 1625 & 240 & - & $1 ; 2 ; 5 ; 7$ \\
Citraconic / itaconic acid* & 1040 & NA & acetic & 7 \\
Formic acid & 1503 & NA & fatty & $1 ; 2 ; 5 ; 7$ \\
Hexanoic acid & 1846 & 3000 & acidic & $1 ; 2 ; 5 ; 7$ \\
Isobutanoic acid & 1570 & 8100 & fatty & $5 ; 7$ \\
Nonanoic acid & 2171 & 3000 & waxy & $2 ; 5 ; 7$ \\
Octanoic acid & 2060 & 3000 & acidic & $1 ; 7$ \\
Propanoic acid & 1535 & 20000 & NA & -
\end{tabular}

Alcohols

$\begin{array}{rcccc}\text { 1-Butanol } & 1142 & 500 & \text { fermented } & 4 ; 7 \\ \text { 1-Hexanol } & 1355 & 800 & \text { herbal } & 1 ; 2 ; 3 ; 5 ; 7 \\ \text { 2,3-Butanediol } & 1543 & 4500 & \text { creamy } & \\ \text { 3-Phenylpropyl alcohol } & 2039 & \text { NA } & \text { balsamic } & 7 \\ \text { 4-Vinylguaiacol } & 2188 & 3 & \text { spicy } & 4 ; 7 \\ \text { Benzyl alcohol } & 1870 & 10000 & \text { floral } & 2 ; 4 ; 7 \\ \text { Chavicol } & 2334 & \text { NA } & \text { phenolic } & \\ \text { 4-Ethylphenol } & 2187 & \text { NA } & \text { smoky } & \\ \text { Phenol } & 2000 & 5900 & \text { phenolic } & \\ \text { 5-methyl-3-hexen-2-ol } & 1274 & \text { NA } & \text { green } & \\ \text { 3-hexen-1-ol } & 1398 & 70 & \text { green } & 2 ; 7 \\ \text { 2-Phenylethyl alcohol } & 1906 & 4 & \text { floral } & 7\end{array}$

Aldehydes

$\begin{array}{rcccc}\text { Hexanal } & 1078 & \text { NA } & - & 7 \\ \text { Esters } & & & \\ \text { 3-Methylbutyl acetate } & 1122 & 2 & \text { fruity } & 3 ; 7 \\ \text { Butyl acetate } & 1074 & 66 & \text { ethereal } & 1 ; 2 ; 3 ; 5 ; 6 ; 7 \\ \text { Ethyl 3-hydroxybutanoate } & 1515 & \text { NA } & \text { fruity } & 7 \\ \text { Ethyl butanoate } & 1035 & 1 & \text { fruity } & 1 ; 3 ; 5 ; 6 ; 7 \\ \text { Ethyl (E)-cinnamate } & 2127 & \text { NA } & \text { balsamic } & 7 \\ \text { Ethyl hexanoate } & 1233 & 1 & \text { fruity } & 1 ; 3 ; 5 ; 6 ; 7 \\ \text { Ethyl isobutanoate } & 961 & 0.1 & \text { fruity } & 7 \\ \text { Isobutyl acetate } & 1012 & 66 & \text { fruity } & 7 \\ \text { Methyl 3-hydroxybutanoate } & 1461 & \text { NA } & \text { apple } & 7\end{array}$


Furans

$\begin{array}{rcccc}\text { 2-Hydroxyfuraneol } & 1518 & \text { NA } & - \\ \text { 5-(Hydroxymethyl)-2-furfural } & 1660 & \text { NA } & \text { fatty } & \\ \text { Furaneol } & 2031 & 0.03 & \text { caramellic } & 1 ; 2 ; 3 ; 4 ; 5 ; 6 ; 7 \\ \text { Mesifurane } & 1580 & 0.03 & \text { musty } & 1 ; 2 ; 3 ; 4 ; 5 ; 6 ; 7\end{array}$

Ketones

1,2-Cyclopentanedione*

1742

2-Hexanone

3-Methyl 2-penten-4-one

3-Penten-2-one

Acetoin

2-hydroxy-4-pyranone

1083

1187

1128

1284

1990

Lactones

delta-Caprolactone
gamma-Caprolactone

1791

1694

gamma-Decalactone

2138

gamma-Dodecalactone

2374

Pantolactone
NA

NA

NA

1.5

800

NA

caramellic

$$
\text { fruity }
$$$$
3 ; 7
$$

vegetable

\begin{tabular}{c|c} 
fruity & 7 \\
buttery & 7
\end{tabular}

$-$

herbal

7

tonka $2 ; 5 ; 7$

fruity

$1 ; 2 ; 3 ; 4 ; 5 ; 7$

fruity

$2 ; 7$

caramellic

4

Terpenes

$\begin{array}{rcccc}\text { alpha-(E,E)-Farnesene } & 1746 & \text { NA } & \text { woody } & \\ \text { beta-Linalool } & 1547 & 6 & \text { floral } & 1 ; 2 ; 3 ; 5 ; 6 ; 7 \\ \text { trans-Linalool oxide (pyranosid) } & 1721 & 320 & \text { floral } & 1 ; 2 ; 5 ; 7 \\ \text { alpha-Muurolene } & 1726 & \text { NA } & \text { woody } & \\ \text { 1-Terpineol } & 1576 & 300 & \text { citrus } & 4 ; 7 \\ \text { trans-Nerolidol } & 2042 & 300 & \text { floral } & 1 ; 2 ; 3 ; 5 ; 7\end{array}$

Others

\begin{tabular}{rcccc} 
Coumaran & 2389 & NA & green tea & \\
Ethyl methyl benzene* & 1225 & NA & - & \\
Ethylene glycol diacetate & 1535 & NA & - & 7 \\
1,1-diethyoxybutane & 990 & NA & - & \\
unknown & 1995 & NA & green & \\
\hline
\end{tabular}

${ }^{\mathrm{a}}$ Identfied by NIST library (version 2.2)

${ }^{\mathrm{b}}$ On polar column (TG Wax)

${ }^{\mathrm{c}}$ References where identified volatiles were also found.

d 1: Larsen et al. (1992); 2: Menager et al. (2004); 3: Schwieterman et al. (2014); 4: Ubeda et al. (2014); 5:

Lambert et al. (1999); 6: Azodanlou et al. (2003); 7: VCF Volatile Compounds in Food database - Strawberry fruit (2007-Feb-08 version 9.1)

*only identified by MS 
Table 3: Number of molecules and quantitative repartition for chemical classes in strawberries free-volatiles

\begin{tabular}{|c|c|c|c|c|c|c|c|c|c|c|c|c|c|c|c|c|c|c|}
\hline \multirow{2}{*}{$\begin{array}{l}\text { TOTAL } \\
\left(\mu \mathrm{g} / \mathrm{kg}^{\mathrm{a}}\right)\end{array}$} & \multicolumn{2}{|c|}{ Acid } & \multicolumn{2}{|c|}{ Alcohol } & \multicolumn{2}{|c|}{ Aldehyde } & \multicolumn{2}{|c|}{ Ester } & \multicolumn{2}{|c|}{ Furan } & \multicolumn{2}{|c|}{ Ketone } & \multicolumn{2}{|c|}{ Lactone } & \multicolumn{2}{|c|}{ Terpene } & \multicolumn{2}{|c|}{ Other } \\
\hline & Number & Ratio & Number & Ratio & Number & Ratio & Number & Ratio & Number & Ratio & Number & Ratio & Number & Ratio & Number & Ratio & Number & Ratio \\
\hline
\end{tabular}

\begin{tabular}{r|c|cc|c} 
Clery & $16608 \pm 1099$ & 6 & $44 \%$ & 3 \\
Darselect & $13187 \pm 2627$ & 2 & $38 \%$ & 1 \\
FCMO060 & $9130 \pm 877$ & 3 & $27 \%$ & 1 \\
Fraise19 & $9769 \pm 1415$ & 4 & $33 \%$ & 1 \\
Honeoye & $34176 \pm 1785$ & 6 & $48 \%$ & 1 \\
Honey & $30505 \pm 1274$ & 7 & $28 \%$ & 5 \\
(Bulgaria) & $21154 \pm 2672$ & 7 & $38 \%$ & 2 \\
Siabel & $22984 \pm 2484$ & 8 & $20 \%$ & 2 \\
Clery PC & $41746 \pm 29012$ & 7 & $3 \%$ & 0 \\
Gariguette & $47980 \pm 7387$ & 10 & $26 \%$ & 1 \\
Clery HS & $95633 \pm 9752$ & 8 & $6 \%$ & 0 \\
CIR121 & $115250 \pm 22173$ & 6 & $5 \%$ & 0 \\
Charlotte & $58259 \pm 7228$ & 8 & $6 \%$ & 0
\end{tabular}

\begin{tabular}{l|l}
$7 \%$ & 0 \\
$1 \%$ & 0 \\
$7 \%$ & 0 \\
$5 \%$ & 0 \\
$2 \%$ & 0 \\
$21 \%$ & 0 \\
$5 \%$ & 0 \\
$7 \%$ & 0 \\
$1 \%$ & 0 \\
$0 \%$ & 0 \\
$0 \%$ & 1 \\
$0 \%$ & 1 \\
$0 \%$ & 1 \\
$0 \%$ & 1
\end{tabular}

\begin{tabular}{l|ll|ll|l}
$0 \%$ & 4 & $15 \%$ & 1 & $13 \%$ & 4 \\
$0 \%$ & 2 & $19 \%$ & 3 & $26 \%$ & 2 \\
$0 \%$ & 1 & $15 \%$ & 1 & $16 \%$ & 1 \\
$0 \%$ & 1 & $13 \%$ & 2 & $13 \%$ & 1 \\
$0 \%$ & 2 & $12 \%$ & 2 & $8 \%$ & 4 \\
$0 \%$ & 3 & $10 \%$ & 2 & $8 \%$ & 4 \\
$0 \%$ & 4 & $11 \%$ & 2 & $19 \%$ & 3 \\
$0 \%$ & 1 & $10 \%$ & 3 & $16 \%$ & 3 \\
$0 \%$ & 2 & $24 \%$ & 2 & $35 \%$ & 3 \\
$0 \%$ & 4 & $90 \%$ & 1 & $1 \%$ & 3 \\
$1 \%$ & 8 & $58 \%$ & 3 & $4 \%$ & 2 \\
$1 \%$ & 5 & $79 \%$ & 2 & $4 \%$ & 2 \\
$1 \%$ & 4 & $84 \%$ & 2 & $2 \%$ & 2 \\
$1 \%$ & 6 & $79 \%$ & 2 & $5 \%$ & 2
\end{tabular}

\begin{tabular}{l|l}
$6 \%$ & 4 \\
$5 \%$ & 3 \\
$4 \%$ & 2 \\
$16 \%$ & 2 \\
$4 \%$ & 4 \\
$12 \%$ & 3 \\
$3 \%$ & 3 \\
$4 \%$ & 3 \\
$5 \%$ & 3 \\
$1 \%$ & 3 \\
$1 \%$ & 1 \\
$1 \%$ & 2 \\
$1 \%$ & 2 \\
$1 \%$ & 1
\end{tabular}

\begin{tabular}{l|}
$4 \%$ \\
$10 \%$ \\
$24 \%$ \\
$14 \%$ \\
$17 \%$ \\
$14 \%$ \\
$5 \%$ \\
$15 \%$ \\
$9 \%$ \\
$0 \%$ \\
$0 \%$ \\
$0 \%$ \\
$4 \%$ \\
$2 \%$
\end{tabular}

\begin{tabular}{l|l}
$3 \%$ & 2 \\
$0 \%$ & 0 \\
$1 \%$ & 1 \\
$1 \%$ & 1 \\
$2 \%$ & 2 \\
$1 \%$ & 2 \\
$2 \%$ & 1 \\
$2 \%$ & 2 \\
$2 \%$ & 2 \\
$1 \%$ & 2 \\
$5 \%$ & $3 \%$ \\
$4 \%$ & 2 \\
$2 \%$ & 2 \\
$2 \%$ & 2
\end{tabular}

\begin{tabular}{l|}
$8 \%$ \\
$0 \%$ \\
$7 \%$ \\
$6 \%$ \\
$6 \%$ \\
$6 \%$ \\
$19 \%$ \\
$2 \%$ \\
$4 \%$ \\
$4 \%$ \\
$4 \%$ \\
$4 \%$ \\
$1 \%$ \\
$5 \%$
\end{tabular} 
Table 4: number of molecules and quantitative repartition of chemical classes in strawberries glycoconjugates

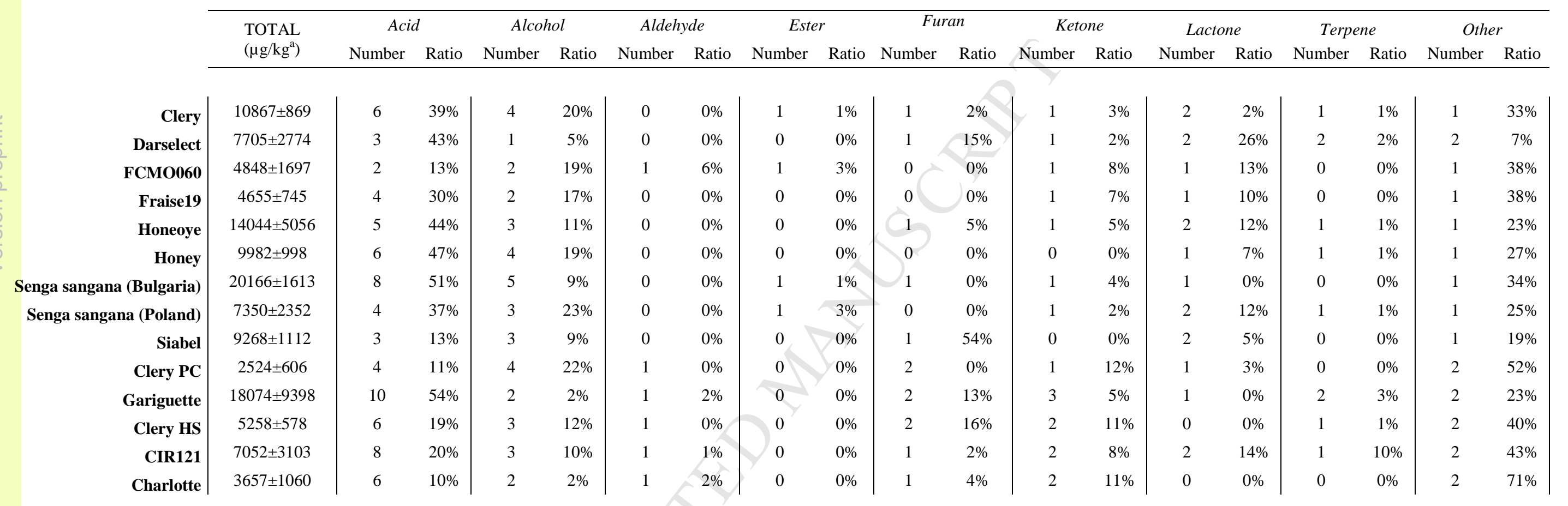

${ }^{a}$ in equivalent 4-nonanol 


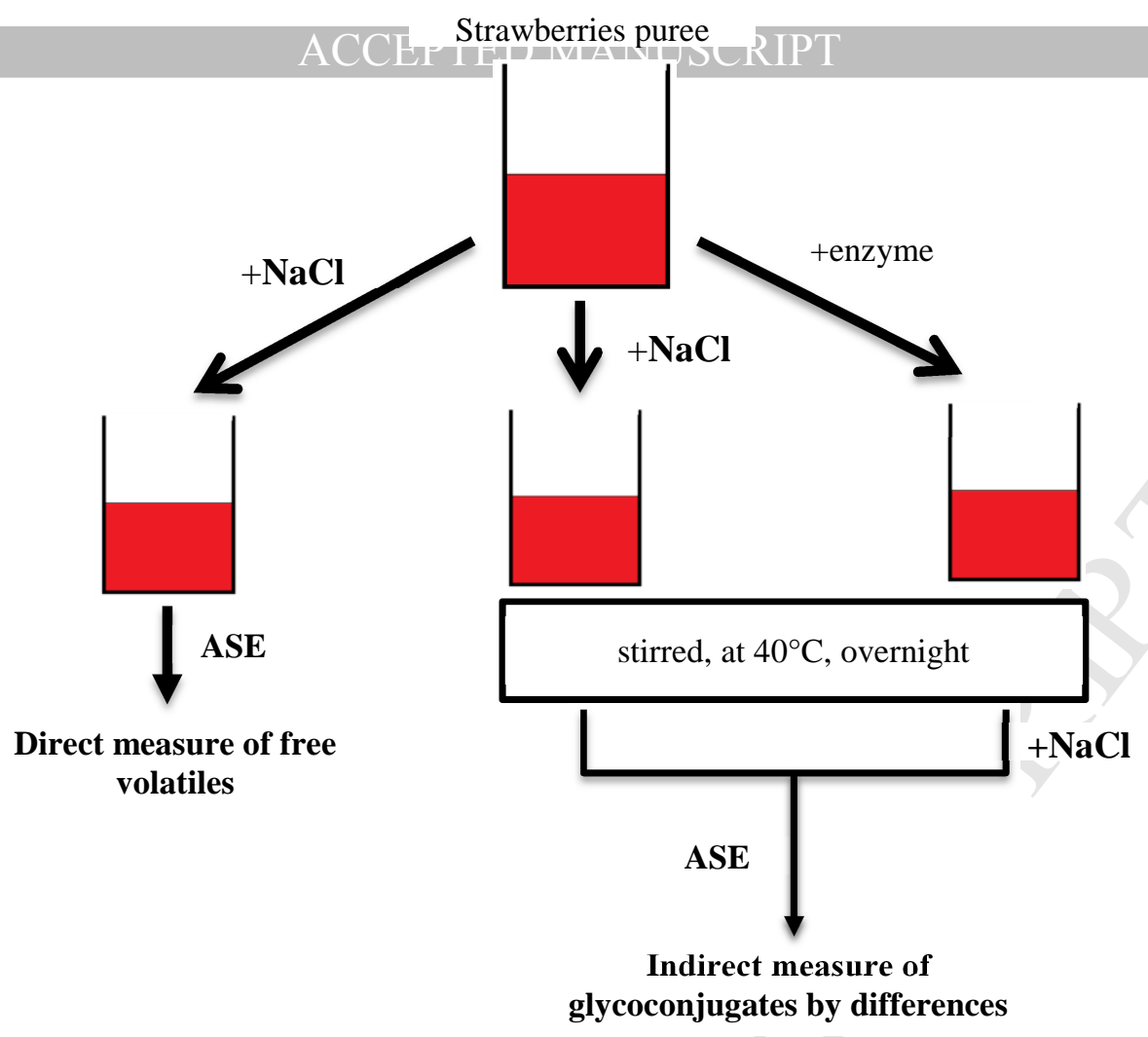

Figure 1: Scheme of strawberries preparation for assisted-solvent extraction (ASE) of volatiles and sampling point for analysis of free- and bound-volatiles 


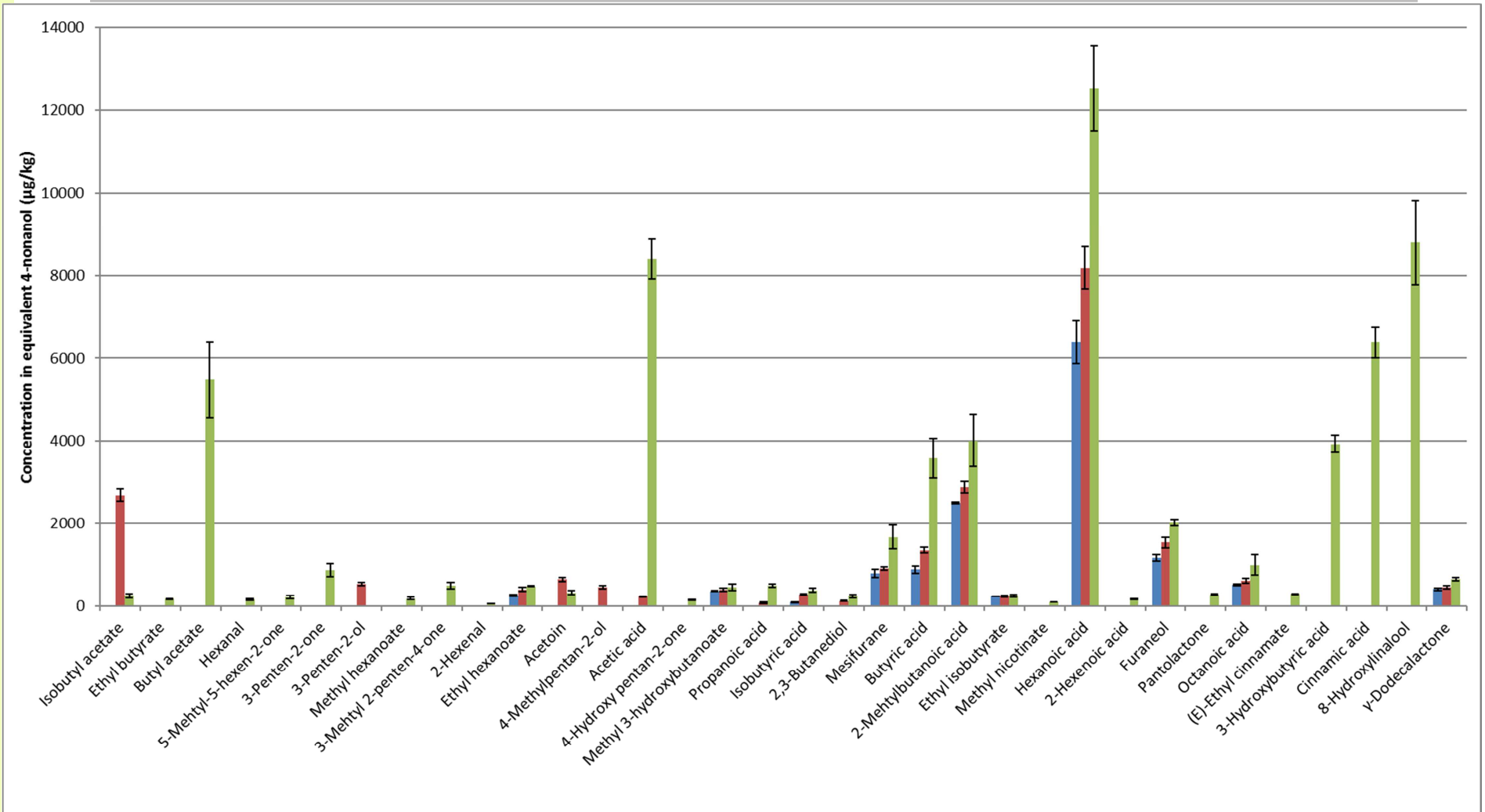

Figure 2: Concentration of volatiles after extraction by ASE method with: dichloromethane/pentane (1:2) (blue), dichloromethane (red), ethyl acetate/pentane (2:1) (green) 


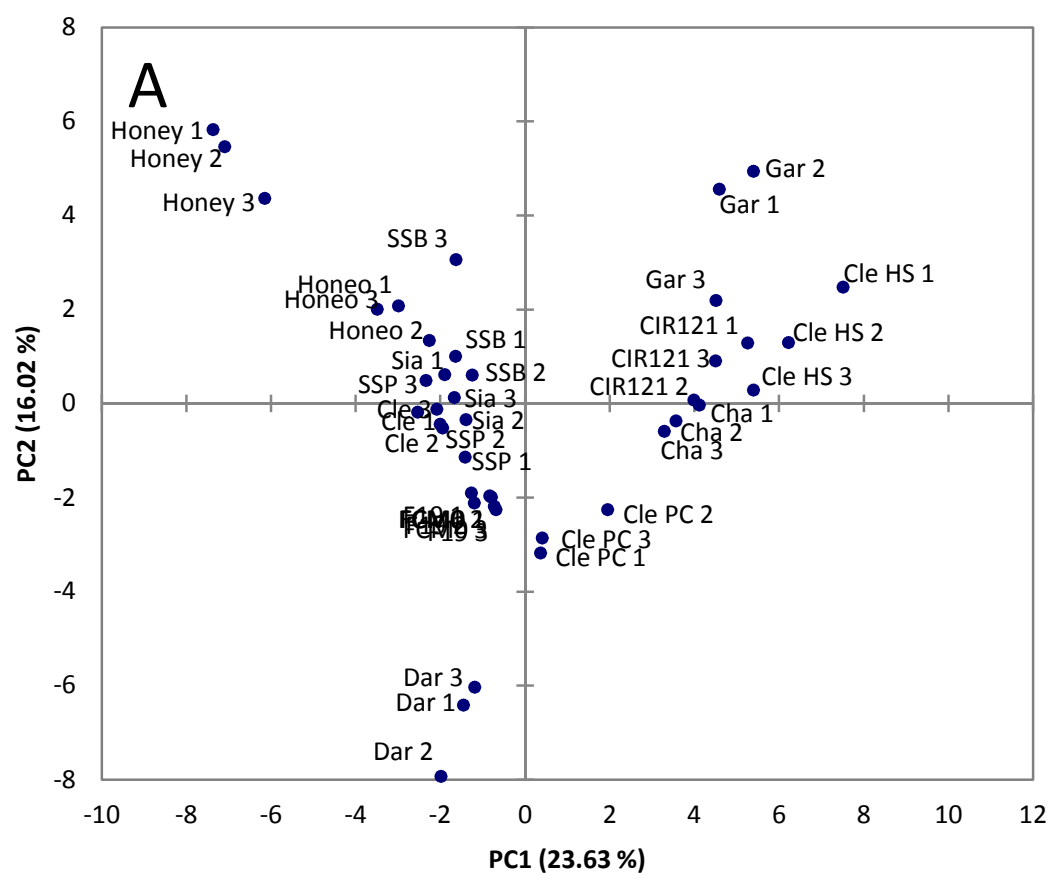

Gar : Gariguette Cha : Charlotte Sia : Siabel F19 : Fraise 19 Honeo : Honeoye Cle : Clery

SSB : Senga sangane (Bulgaria) SSP : Senga sangana (Poland) Dar : Darselect

1. Furaneol

2. Mesifurane

3. Isobutanoic acid

4. 2-Methylbutanoic acid

5. Ethyl Isobutanoate

6. 2-Hexenoic acid

7. Unknown

8. Trans-Nerolidol

9. Methyl 3-hydroxybutanoate

10. Succinic anhydride

11. 2-Hydoxyfuraneol

12. Propanoic acid

13. Crotonic acid

14. Hexanal

15. Ethyl butanoate

16. 2-Hexanone

17. Isobutyl acetate

18. 3-Methylbutyl acetate

19. 1,1-diethoxybutane

20. Butyl acetate

21. $\alpha$-(E,E)-Farnesene

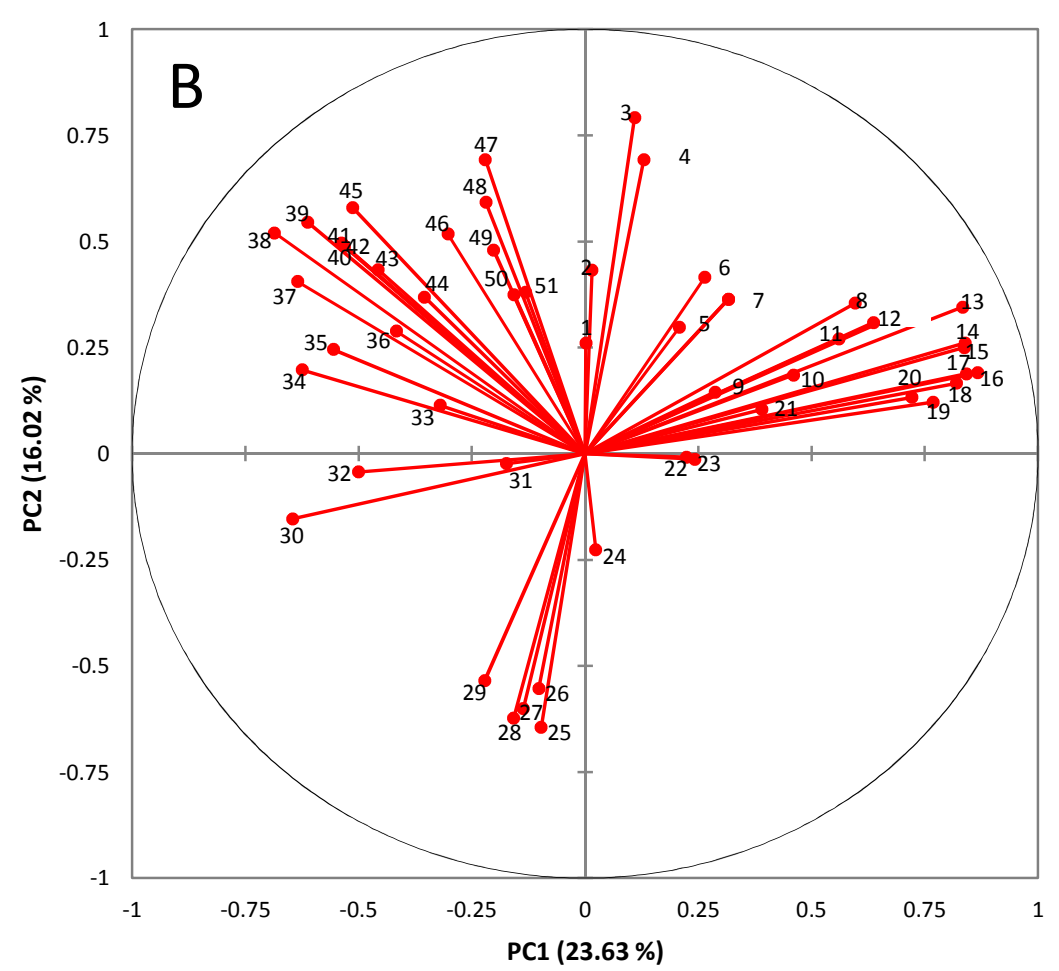

22. Trans-linalool oxide

23. 3-Methylhexanoic acid

24. 4-Vinylguaiacol

25. Benzyl alcohol

26. $\delta$-Caprolactone

27. $\gamma$-Caprolactone

28. 5-(Hydroxymethyl)-2-furfural

29. Octanoic acid

30. 3-Methyl-3-penten-2-one

31. Chavicol

32. 3-Penten-2-one

33. 5-Methyl-5-hexen-2-one

34. 1-Butanol

35. 2-Phenylethyl alcohol

36. Nonanoic acid

37. Ethylene glycol monoacetate

38. Pantolactone

39. 2,3-Butanediol

40. 3-Phenylpropyl alcohol

41. Ethyl phenol

42. Ethyl (E)-cinnamate

43. 1-Hexanol

44. $\gamma$-Decalactone

45. Acetoin

46. Ethyl hexanoate

47. Butanoic acid

48. Hexanoic acid

49. Coumaran

50. $\beta$-Linalool

51. $\gamma$-Dodecalactone

Figure 3: Principal component analysis of free-volatiles in strawberries. A. Sample map; B. Variable correlation map 


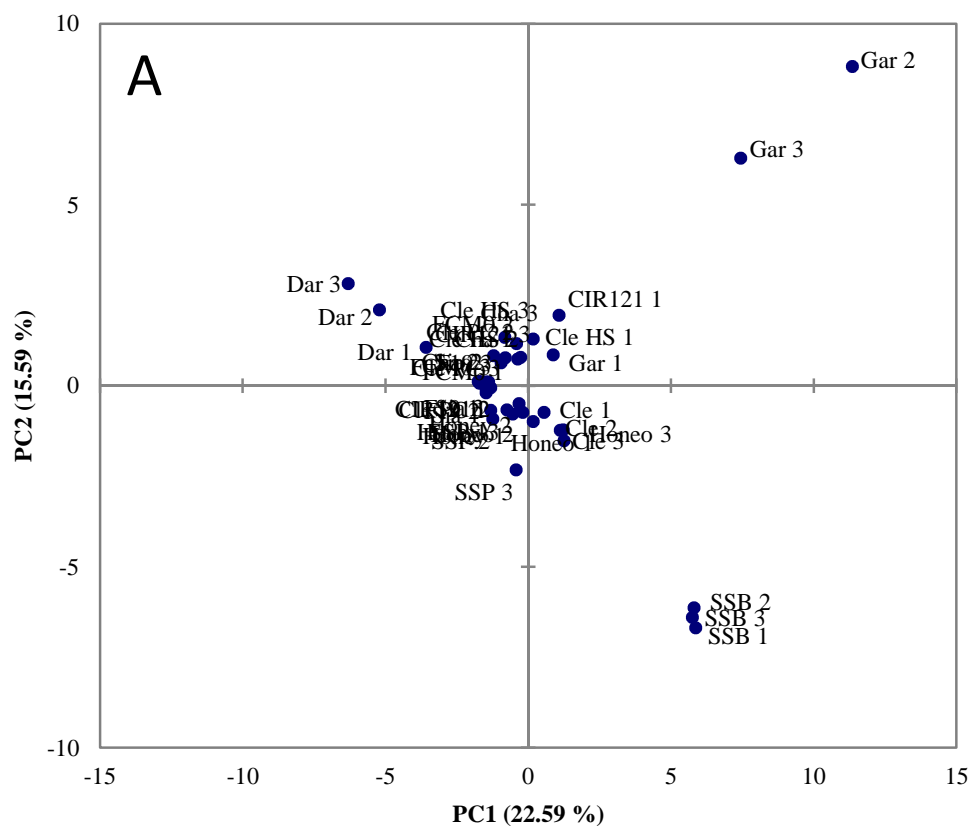

Gar : Gariguette

Cha : Charlotte

Sia : Siabel

F19: Fraise 19

Honeo : Honeoye

Cle : Clery

SSB : Senga sangane (Bulgaria)

SSP : Senga sangana (Poland)

Dar : Darselect

1. Benzyl alcohol

2. Ethyl phenol

3. Nonanoic acid

4. 3-Methylbutyl acetate

5. $\gamma$-Decalactone

6. 5-(Hydroxymethyl)-2-furfural

7. Octanoic acid

8. 3-Methyl-3-penten-2-one

9. Linalool oxide

10. Methylethylbenzene

11. 1-Terpineol

12. $\gamma$-Caprolactone

13. Furaneol

14. 2-hydroxy-4-pyranone

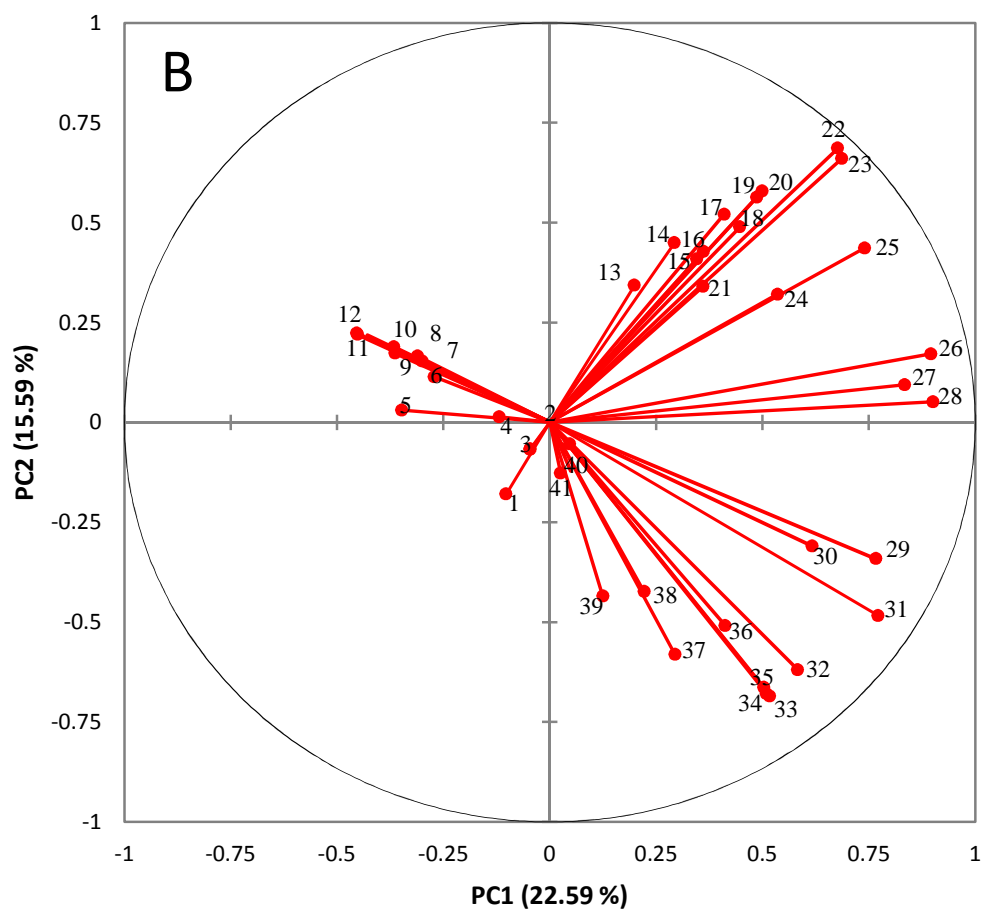

15. Trans-Nerolidol

16. $\gamma$-Dodecalactone

17. Hexanal

18. Succinic anhydride

19. 2-Hexanone

20. 1,1-diethoxybutane

21. Formic acid

22. Propanoic acid

23. Acetoin

24. 2-Hydroxyfuraneol

25. Isobutanoic acid

26. 2-Methylbutanoic acid

27. Butanoic acid

28. Crotonic acid

29. $\beta$-Linalool

30. Hexanoic acid

31. Coumaran

32. 2-Hexenoic acid

33. Phenol

34. 3-Hexenoic acid

35. 1,2-cyclopentadione

36. 4-Vinylguaiacol

37. Methyl 3-hydroxybutanoate

38. Pantolactone

39. 2,3-Butanediol

40. Chavicol

41. 2-Phenylethyl alcohol

Figure 4: Principal component analysis of glycoconjugates in strawberries. A. Sample map ; B. Variable correlation map 


\section{Highlights:}

Glycosylated volatiles can be reliably analyzed by direct enzymatic hydrolysis of the fruit.

Free-volatile profiles split strawberries for fresh market and for processing.

Bound-volatile profiles were similar among the majority of strawberry varieties.

Strawberries for processing were the best candidates for aroma enhancement. 